\title{
Do Estrogens Effectively Prevent Osteoporosis-Related Fractures?
}

\author{
J.-Y. Reginster, ${ }^{1,2,3,4}$ O. Bruyere, ${ }^{1,2}$ M. Audran, ${ }^{5}$ B. Avouac, ${ }^{6}$ J.-J. Body, ${ }^{7}$ G. Bouvenot, ${ }^{8}$ M.-L. Brandi, ${ }^{9}$ \\ C. Gennari, ${ }^{10}$ J.-M. Kaufman, ${ }^{11}$ E.-M. Lemmel, ${ }^{12}$ L. Vanhaelst, ${ }^{13}$ G. Weryha, ${ }^{14}$ J.-P. Devogelaer, ${ }^{15}$ \\ On behalf of the Group for the Respect of Ethics and Excellence in Science (GREES)
}

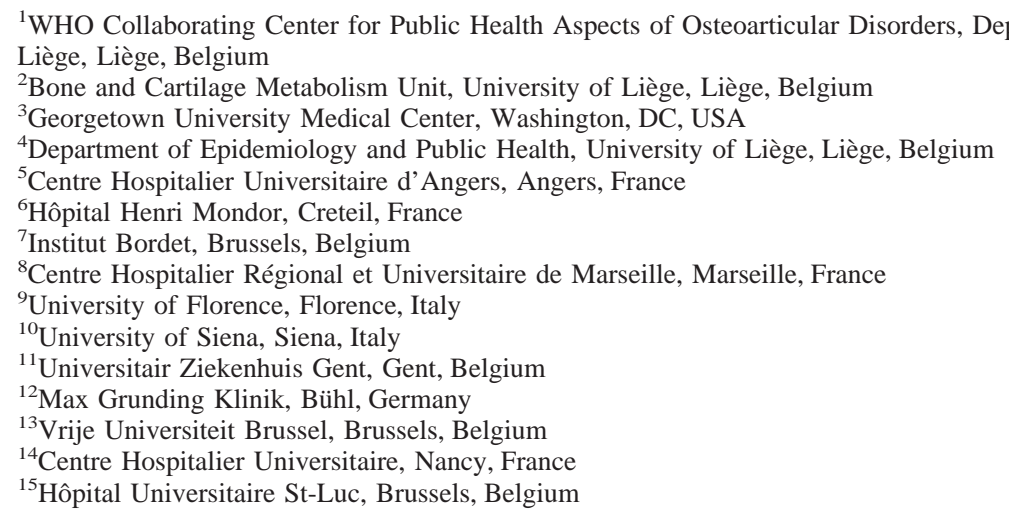

Received: 29 October 1999 / Accepted: 30 March 2000

Since Albright, [1] some 60 years ago, reported the beneficial effects of estrogens for decreasing urinary calcium excretion and suggested that these harmones might be useful in preventing postmenopausal osteoporosis, estrogen replacement therapy (ERT) has been consistently regarded as the first choice for prevention of trabecular and cortical bone loss in postmenopausal women [2-5]. However, serious controversies remain over the cost/effectiveness of treating every woman at the time of menopause [6], the optimal timing for starting ERT [5], the minimal effective dose of ERT acting on bone [7], and the duration of ERT needed to prevent osteoporotic fractures [8]. The effectiveness of ERT for preventing osteoporosis-related fractures is undisputed and requirements for marketing authorization for ERT products have lightened compared with current requests for other therapeutic medications developed in this field $[9,10]$. However, although the skeletal benefits of ERT for preventing trabecular or cortical bone loss can hardly be challenged, one might be wary of published evidence that prolonged ERT use unequivocally reduces the risk of hip fracture. Controlled clinical trials and systematic reviews were located using Medline 1970-1999 and EMBASE 1980-1999. Since 1985 we have searched scien-

Correspondence to: J.-Y. Reginster, CHU Sart Tilman, Bâtiment B23, 4000 Liège, Belgique tific journals on bone and bibliographies of review articles. All prospective controlled trials were included for evaluation of the effects of hormone replacement therapy (HRT) on bone loss. A total of 57 prospective controlled trials were identified, 46 of which were randomized clinical trials (RCTs) and 15 were double blinded. All clinical trials assessing the effects of HRT on fracture rates were considered. Two RCTs and one systematic review were identified [11].

In the 46 randomized controlled trials comparing estrogen (with or without progestins) (HRT) with placebo or calcium on bone loss prevention, the study population varied from 14 to 875 women and the duration was from .5 to 10 years. In general, they drew similar conclusions, i.e, that estrogen intervention reduces the rate of postmenopausal bone loss at trabecular and cortical sites. An early doubleblind trial [12] reported the preventive effects of HRT on cortical (metacarpal) bone loss for up to 10 years. More recent double-blind, placebo-controlled, randomized clinical trials confirmed these findings for oral [13], percutaneous $[14,15]$, or transdermal [16] estrogens at the spine [13, $14,16]$, the forearm [16], and/or the hip $[13,16]$ for up to 3 years. Two prospective open studies $[17,18]$ showed similar results for estrogen implants after 1 year. When standardized for technique used for bone mineral density (BMD) assessment, the magnitude of the point estimate differences between the HRT and the control group varied greatly from one study to another, depending upon the dose of HRT used (dose-related effect on bone mass in most 
randomized controlled trials), skeletal site measured (effect more pronounced on trabecular bone), age of the population (effect more pronounced early after the menopause) [19], and the nature of the combined progestins (trivial effect of progestins except for norethisterone acetate that synergistically acts with estrogens to increase bone mass) [20, 21]. Though evidence that HRT prevents postmenopausal bone loss is strong, studies providing direct demonstration of a reduction in fracture rates as a consequence of HRT intake are more scarce and subject to controversy.

No systematic review has evaluated the effect of HRT on vertebral fracture rates. In one single, double-blind, randomized, controlled trial [16], 75 postmenopausal women (47-75 years) with one or more prevalent vertebral fractures, were randomized to transdermal HRT (17 $\beta$ estradiol and oral medroxyprogesterone acetate) or placebo. After 12 months, 8 new fractures occurred in 7 women in the estrogen group whereas 20 occurred in 12 women in the placebo group, yielding a lower vertebral fracture rate in the estrogen group $(\mathrm{RR}=0.39,95 \% \mathrm{CI}=0.16-0.95)$. However, these results were based on the number of fractures per person-years (23 versus 58/100). When expressing the results as the number of patients having experienced a new vertebral fracture, as recommended in regulatory guidelines [10] the difference between 7 women suffering fractures in HRT and 12 in placebo is no longer statistically significant. A group of 100 postmenopausal women who had previously taken part in a randomized controlled trial were reviewed afer a median follow-up period of 9 years [22]. An indirect measurement (total spine score) of the prevalence of vertebral fracture revealed a significant $(P<0.01)$ difference in favor of estrogen users compared with placebo-treated patients, whereas other indices (absolute difference in anterior height and ratio of central vertebral height to anterior height of vertebrae) failed to achieve significance. In a case-control study published first as a retrospective survey of 490 women followed for an average of 17.6 years [23], and later as the same cohort followed for an additional average of 8 years [24], RR for vertebral and wrist fractures in estrogen users were $0.57(95 \% \mathrm{CI}=0.41-0.80)$ and $0.55(95 \% \mathrm{CI}$ $=0.32-0.92)$, respectively.

For nonvertebral fractures, one systematic review of the literature published between 1970 and 1991 is available [25]. From the analysis 11 epidemiological studies (6 casecontrol and 5 cohort), the authors concluded that the pooled estimates of the relative risk for hip fracture comparing ever-users of estrogen with nonusers was 0.75 (95\% CI = $0.68-0.84)$. Since that time, two randomized controlled trials and five epidemiological studies have evaluated the effect of HRT on nonspinal osteoporotic fractures. A doubleblind, placebo-controlled, randomized trial was primarily designed to evaluate the effect of HRT on secondary prevention of coronary heart disease, assessment of fractures being only a secondary endpoint. After following 2763 postmenopausal women younger than 90 years of age for an average of 4.1 years, the authors found no difference between estrogen and placebo users for hip fracture (12 in the HRT group versus 11 in the placebo group) $(\mathrm{RR}=1.10$ : $95 \% \mathrm{CI}=0.49-2.50)$ or any fracture $(\mathrm{RR}=0.95 ; 95 \% \mathrm{CI}$ $=0.75-1.21)[26]$.

One can argue that in this study, fracture reduction was not the primary endpoint, the overall number of hip fracture was too low to draw significant conclusions, the study was not powered to assess this outcome, the study population was not selected on the basis of risk factors for osteoporosis, and that some doubts remain regarding fracture data collec- tion. However, the most worrisome fact is not the absence of significant reduction in hip fractures but that the absolute number of hip fractures did not even show a trend in favor of HRT users.

From an open, randomized, controlled trial [27] having included 464 postmenopausal women, 368 were followed for a mean duration of 4.3 years. The estimate risk of new symptomatic nonvertebral fractures among women treated with HRT alone was $0.29(95 \% \mathrm{CI}=0.10-0.90)$ whereas it was nonsignificant in women receiving a combination of HRT and vitamin D $(\mathrm{RR}=0.44 ; 95 \% \mathrm{CI}=0.17-1.15)$ compared with the placebo group (adjusted by femoral density and previous fractures).

From the five epidemiological studies, three were prospective cohort studies and two retrospective, case-control trials. In the DUBBO study [28] (1091 women), mean age 70 years, followed prospectively between 1989 and 1993, the incidence of atraumatic fractures (any site) among nonestrogen users was not significantly different than that of estrogen users $(\mathrm{OR}=1.06 ; 95 \% \mathrm{CI}=0.94-1.16)$.

The follow-up of the Framingham study through examination 19 (2873 women originally recruited and 948 attending examination 19) [29] also revealed that current estrogen intake was not significantly linked to a reduction in hip fracture $(\mathrm{OR}=0.38 ; 95 \% \mathrm{CI}=0.12-1.21)$.

More recently, the analysis of the "Study of Osteoporotic Fracture" (SOF) [15] (9704 women, 65 years of age or older, followed during an average of 4.6 years) concluded that current estrogen use was associated with a decrease in the risk for wrist fracture $(\mathrm{RR}=0.39 ; 95 \% \mathrm{CI}=0.24$ $0.64)$ and for all nonspinal fractures $(\mathrm{RR}=0.66 ; 95 \% \mathrm{CI}$ $=0.54-0.80)$ when compared with nonestrogen users. The risk for hip fracture was not significantly different between current users and never-users $(\mathrm{RR}=0.60 ; 95 \% \mathrm{CI}=0.36$ 1.02). However, current users who had started HRT within 5 years of menopause had a decreased risk of hip fracture $(\mathrm{RR}=0.29 ; 95 \% \mathrm{CI}=0.09-0.92)$, wrist fracture $(\mathrm{RR}=$ $0.29 ; 95 \% \mathrm{CI}=0.13-0.68)$, and all nonspinal fractures $(\mathrm{RR}$ $=0.50 ; 95 \% \mathrm{CI}=0.36-0.70)$. The authors of this prospective cohort study concluded that for protection against fracture, estrogen should be initiated soon after the menopause and continued indefinitely [8].

The two retrospective case-control studies are the MEDOS study [30] (2086 women with hip fractures and 3582 controls) and the Swedish hip fracture study [31, 32] (1328 incident cases with hip fracture and 3312 randomly selected controls). In the MEDOS study, the relative risk of hip fracture in women taking estrogen was 0.55 (95\% CI = 0.31-0.85). In the Swedish study, current estrogen users were significantly protected against hip fracture $(\mathrm{OR}+0.35$ $95 \%$ CI $=0.24-0.53$ ) whereas no significant difference was observed for former users $(\mathrm{OR}=0.76$; $95 \% \mathrm{CI}=$ 0.57-1.01). The protective effect of estrogens was substantially diminished after 5 years of HRT cessation $(-7 \%$ to $-48 \%$ ). In view of these results, the problem of long-term compliance of postmenopausal women with HRT becomes even more critical.

Several cross-sectional or retrospective studies have addressed this issue in daily practice. From the SOF cohort (9704 non-black women aged 65 and older), 17.1\% of the women between 65 and 69 years reported current use of oral estrogens but only $3.9 \%$ of women 85 years and older were currently using oral estrogens [33]. From the database of the Kayser Foundation Health Plan [39] (1532 women >45 years old who initially filled index prescription for 0.625 $\mathrm{mg}$ /day of conjugated estrogens), the probability of continu- 
ing HRT for 36 months varied between 0.19 (continuous combined estrogens-progestin therapy) and 0.24 (cyclic combination therapy adding progestin to estrogens) [40]. Even worse results reported from a survey of five group practices of Dutch general practitioners (1689 women aged 45-60 years) where the mean duration of HRT use (main indication for prescription was menopausal complaints) was 7 months and only $8 \%$ of the women remained on HRT for more than 2 years (41). In the United Kingdom (400 postmenopausal women aged 40-69 years), prescription of HRT because of increased risk for osteoporosis resulted in $40 \%$ of women with low BMD not taking HRT 8 months after referral (42). In all surveys, the main reasons for stopping HRT were anxiety over possible side-effects, especially breast cancer, weight gain, and bleeding.

The purpose of the present editorial is not to challenge the overall benefit of HRT in postmenopausal women. Extraskeletal benefits of ERT or HRT have been extensively discussed elsewhere. (see 43). Our concern is the preferential treatment given to HRT products compared with other currently developed medications, where evidence of an antifracture efficacy at the level of the spine or hip is requested. We are convinced that if any new chemical entity other than the one currently available for ERT or HRT, i.e., bisphosphonates, calcitonin, or SERMS, were filing for marketing authorization with such a limited demonstration of antifracture efficacy it would most likely be poorly received both by regulatory authorities and the scientific community.

We agree that initiating a double-blind, placebocontrolled prospective study evaluating the antifracture benefit of HRT on the spine or the hip would not only be a methodological challenge but also somewhat unethical in view of the extraskeletal benefits of HRT. However, in view of appropriate published studies demonstrating the antifracture efficacy of antiosteoporotic drugs, an open prospective equivalent trial comparing HRT to these drugs, with spine or hip fracture reduction as a primary endpoint, would scientifically validate the currently widespread dogma that HRT should be used for life by postmenopausal women to prevent osteoporosis-related fractures.

\section{References}

1. Albright F (1941) Postmenopausal osteoporosis. JAMA 116: 2465

2. Rosen CJ, Kessenich CR (1997) The pathophysiology and treatment of postmenopausal osteoporosis. An evidence-based approach to estrogen replacement therapy. Endocrin Metab Clin North Am 26:295-311

3. Eastell R (1998) Treatment of postmenopausal osteoporosis. N Engl J Med 338:736-746

4. Lindsay R (1987) Estrogen therapy in the prevention and management of osteoporosis. Am J Obstet Gynecol 156:13471351

5. Ott S (1992) Estrogen therapy for osteoporosis-even in the elderly. Ann Int Med 117:85-86

6. Tosteson A, Rosenthal DI, Melton LJ, Weinstein MC (1990) Cost effectiveness of screening perimenopausal white women for osteoporosis: bone densitometry and hormone replacement therapy. Ann Intern Med 113:594-603

7. Genant HK, Lucas J, Weiss S, et al. (1997) Low-dose esterified estrogen therapy. Arch Intern Med 157:2609-2615

8. Cauley JA, Seeley DG, Ensrud K, et al. (1995) Estrogen re- placement therapy and fractures in older women. Ann Intern Med 122:9-16

9. Guidelines for preclinical and clinical evaluation of agents used in the prevention or treatment of postmenopausal osteoporosis April, 1994. The FDA published Good Guidance Practices, February 1997

10. Note for Guidance on Involutional Osteoporosis in Women. EMEA/CPMP/EWP/552/95

11. Bland CJ, Meurer LN, Maldonado G (1995) A systematic approach to conducting a non-statistical meta-analysis of research literature. Acad Med 70:642-653

12. Nachtigall L, Nachtigall R, Beckman E (1979) Estrogen replacement therapy I: a 10-year prospective study in the relationship to osteoporosis. Obstet Gynecol 53:277-281

13. Genant H, Lucas J, Weiss S et al. Low-dose esterified estrogen therapy. Arch Intern Med 157:2609-2615

14. Riis B, Thomsen K, Strom V (1987) The effect of percutaneous estradiol and natural progesterone on postmenopausal bone loss. Am J Obstet Gynecol 156:61-66

15. Devogelaer JP, Lecart C, Dupret P, et al. Long-term effects of percutaneous estradiol on bone loss and bone metabolism in postmenopausal hysterectomized women. Maturitas 28:243249

16. Lufkin E, Wahner H, O'Fallon W, et al. (1992) Treatment of postmenopausal osteoporosis with transdermal estrogen. Ann Int Med 117:1-9

17. Holland E, Leather A, Studd J (1995) Increase in bone mass of older postmenopausal women with low mineral bone density after one year of percutaneous oestradiol implants. Br J Obstet Gynecol 102:238-242

18. Holland E, Leather A, Studd J (1994) The effect of 25-mg percutaneous estradiol implants on the bone mass of postmenopausal women. Obstet Gynecol 83:43-46

19. Quigley M, Martin P, Bumier A, et al. Estrogen therapy arrests bone loss in elderly women. Am J Obstet Gynecol 156:15161523

20. The Writing Group for the PEPI trial (1996) Effects of hormone therapy on bone mineral density. JAMA 276:13891396

21. Christiansen C, Riis B (1990) 17ß-estradiol and continuous norethisterone: a unique treatment for established osteoporosis in elderly women. J Clin Endocrinol Metab 71:836-841

22. Lindsay R (1980) Prevention of spinal osteoporosis in oophorectomised women. Lancet 1:1152-1154

23. Ettinger B, Genant H, Cann C (1985) Long-term estrogen replacement therapy prevents bone loss and fractures. Ann Int Med 102:319-324

24. Maxim P, Ettinger B, Spitalny M (1995) Fracture protection provided by long-term estrogen treatment. Osteoporosis Int 5:23-29

25. Grady D, Rubin S, Petitti D, et al. (1992) Hormone therapy to prevent disease and prolong life in postmenopausal women. Ann Int Med 17:1016-1037

26. Hulley S, Grady D, Bush T (1998) Randomized trial of estrogen plus progestin for secondary prevention of coronary heart disease in postmenopausal women. JAMA 280:605-613

27. Komulainen M, Kroger H, Tupurainen M, et al. (1998) HRT and Vit $\mathrm{D}$ in prevention of nonvertebral fractures in postmenopausal women: a 5-year randomized trial. Maturitas 31:45-54

28. Nguyen T, Jones G, Sambrook N, et al. (1995) Effects of estrogen exposure and reproductive factors on bone mineral density and osteoporotic fractures. J Clin Endocrinol Metab 80:2709-2714

29. Kiel D, Baron J, Anderson J, et al. (1992) Smoking eliminates the protective effect of oral estrogens on the risk for hip fracture among women. Ann Int Med 116:716-721

30. Kanis J, Johnell O, Guliberg B, et al. (1992) Evidence for efficacy of drugs affecting bone metabolism in preventing hip fracture. Br Med J 305:1124-1128 
31. Michaelson K, Baron J, Farahmand B, et al. on behalf of the Swedish Hip Fracture Study Group (1998) Hormone replacement therapy and risk of hip fracture: population-based casecontrol study. Br Med J 316:1858-1863

32. Michaelson K, Baron J, Johnell O, et al. for the Swedish Hip Fracture Study Group. (1998) Variation in the efficacy of hormone replacement therapy in the prevention of hip fracture. Osteoporosis Int 8; 540-546

33. Cauley J, Cummings S, Black D, et al. (1990) Prevalence and determinants of estrogen replacement therapy in elderly women. Am J Obstet Gynecol 163:1438-1444

34. Ettinger B, Li D, Lein R (1996) Continuation of postmeno- pausal hormone replacement therapy: comparison of cyclic versus continuous combined schedules. Menopause 3:185189

35. Groeneveld F, Bareman F, Barentsen R, et al. (1998) Duration of hormonal replacement therapy in general practice: a followup study. Maturitas 29:125-131

36. Ryan P, Harrison R, Blake G, et al. (1992) Compliance with hormone replacement therapy (HRT) after screening for postmenopausal osteoporosis. Br J Obstet Gynecol 99:325-328

37. Lindsay R, Bush TL, Grady D, et al. (1996) Therapeutic controversy-estrogen replacement in menopause. J Clin Endocrinol Metab 81:3829-3838 